\title{
USE OF BIM WITH PHOTOGRAMMETRY SUPPORT IN SMALL CONSTRUCTION PROJECTS. CASE STUDY FOR COMMERCIAL FRANCHISES
}

\author{
Antonio J. LOREDO CONDE ${ }^{1}$, Justo GARCÍA-SANZ-CALCEDO ${ }^{\circledR 2}{ }^{*}$, \\ Antonio M. REYES RODRÍGUEZ ${ }^{2}$ \\ ${ }^{1}$ Country Expansion Department LBP, Mérida, Spain \\ ${ }^{2}$ Department of Graphic Expression, University of Extremadura, Badajoz, Spain
}

Received 3 August 2019; accepted 19 December 2019

\begin{abstract}
Building Information Modelling for small constructions is a useful working tool aimed at providing alternative solutions in building engineering. However, it is not commonly applied to this purpose, and even less together with photogrammetry techniques. This work seeks to analyse the advantages of this methodology with photogrammetry support insmall projects. To this end, 121 commercial franchise projects in the field of perfume and cosmetic industry were studied in order to assess the benefits of BIM methodology. These projects were developed between 2011 and 2016. BIM protocols were shown to achieve $20 \%$ reduction in costs per project and in working periods ( 4.11 days), which led to a productivity improvement exceeding $27 \%$. The total period until opening to public was observed to decrease in 10.09 days, and the number of inquiries and doubts during the project execution phase handled by the construction companies were seen to reduce by $25 \%$. Moreover, the return of investment (ROI) corresponding to the implementation of BIM protocols was found to be more favourable than that of CAD (41.88\%), with associated internal rate of return (IRR) of $34.5 \%$. The validity of the results is limited to the scope of works for small commercial premises.
\end{abstract}

Keywords: BIM, small construction, photogrammetry, franchise, ROI, project management.

\section{Introduction}

BIM (Building Information Modelling) background arises to provide solutions in the ambit of engineering and construction. The core concept of this methodology (Santos et al., 2019) lies in the implementation of a single database accounting for all the information of a building, so that potential collisions among the different services or equipment of the building are easily identified and handled. The application of BIM protocols to small projects gives birth to the so-called "Little BIM" (Jernigan, 2008), which is commonly used in small projects (Dainty et al., 2017).

The particular pattern of franchises, which involves the repetition of certain fixed elements in shops, is a key factor that features BIM methodology as a suitable tool for the sector. However, it has not been implemented in a generalized routine yet, nor have its potential benefits been capitalized so far (Zou et al., 2017). The fact of filling this technological gap could be a great opportunity to improve this sector. The lack of a global implementation of BIM is linked to the potential risks and challenges that might inhibit its effectiveness (Sun et al., 2017a).
An assessment model for the level of success of the use of BIM in projects, known as Success Level Assessment Model (SLAM BIM), has elsewhere been reported (Won \& Lee, 2016); the advantages of BIM methodology in terms of execution time and costs were identified, but no assessment on final quality and fidelity provided by BIM was accounted for. Other authors have reported case studies on similar industrial projects implemented according to BIM protocols as compared to those following traditional approaches (Barlish \& Sullivan, 2012; Doumbouya et al., 2016). For such purpose, cost or investment metrics along with benefit or return metrics were accounted for, and BIM methodology was proved to show a high profit potential, with variable real investments and returns for each project (Ghaffarianhoseini et al., 2017).

Several methods for BIM-based progress monitoring have been proposed in last years (Omar \& Nehdi, 2016). There are several available platforms for virtual decoration which are suitable for simulations involving colours, furniture, lighting, etc. However, they are restricted to

*Corresponding author. E-mail: jgsanz@unex.es 
visual and graphic aspects and show a low degree of customization, given that libraries of elements are designed previously according to commercial aspects set by the software designer and the potential user (Moayeri et al., 2017). Some other former studies report on the design of virtual 3D models from data generated by oblique photogrammetry, with at least three photograms of overlapping areas (Sun et al., 2017b), which require the subsequent use of a specific post-processing software (Arévalo Vera et al., 2015).

The automatic identification of recurrent similar configurations in construction processes, known as process patterns (Sigalov \& König, 2017), are of great aid for the design of virtual models and the characterization of elements. The so-identified process patterns might be further generalized, which supports the relevance of the design of process templates.

Up to date, it is still common for most construction projects to be developed according to CAD protocols, with specific data collection systems which are not linked to metadata and which provide 2D final graphic solutions (Khaja et al., 2016). Previous quantitative studies have reported on the feasibility of 4D planning of graphic systems versus conventional systems in construction projects, to conclude that even though conventional planning was shown to be $20 \%$ faster than $4 \mathrm{D}$ simulation, the latter was featured as $40 \%$ more efficient in terms of visual monitoring of the process and also $40 \%$ more efficient in terms of data updating (Candelario-Garrido et al., 2017).

It is therefore appropriate to scan the advantages of BIM methodology in the implementation process of commercial franchises by the joint use of BIM and photogrammetry (Li, 2014), as compared to the standard CAD working protocols (Giel \& Issa, 2013). This way, the improvement of both measuring and decision-making processes would be guaranteed by the use of new technologies and BIM systems supported by photogrammetry. The analysis of the camera's calibration (Wang et al., 2012) and the presentation of results by rendered images would definitively help the implementation of the project in terms of time and associated costs. This is particularly suitable for franchises' models and elements, given that they show a repetitive pattern, and yields a profitability plus for the franchisee, who will achieve brand's recognition due to the geographic dispersion of stores sharing the same appearance and operating under a common advertising policy (Solís-Rodríguez \& González-Díaz, 2017).

Lévy (2011) adapted the BIM technology to smallscale sustainable design for architects who carry out small and/or medium scale projects, and are also committed to sustainable development. Zhang et al. (2014) studied the influence of BIM in medium construction project costs, and pointed out the disadvantages of traditional cost control methods. They introduced the effect of BIM on cost control in different stages of a building life-cycle. Koranda et al. (2012) examined projects of different sizes and in dif- ferent environments within the Midwestern United States to determine those aspects that hinder the integration of lean concepts for small construction projects.

Sanhudo et al. (2020) introduced a full-fledged laser scanning framework for geometric data acquisition, comprising the entire spectrum, including planning, surveying and data analysis; the result is a framework that details the necessary steps to acquire a point cloud that is applicable to BIM modelling. Mill et al. (2014) showed that it is possible to detect damages in the facade building by integration of the laser scanning point cloud and further elaboration of the BIM model.

Braun et al. (2015) evaluated on a study case scenario photogrammetric production through point cloud technique in order to monitor construction progress. They also compared as-planned and as-built procedures based on the geometry. Tuttas et al. (2015) compared a BIM state of a building (as-planned) to a photogrammetric point cloud (as-built). They showed that the label built is reliable and can be used for further analysis.

BIM technology requires an advanced parametric representation of the geometry, involving spatial relationships, constraints and material properties. Barazzetti et al. (2015) proposed a BIM-based reconstruction methodology that preserves the level of detail in photogrammetric and laser-scanning point clouds, and relies on non-uniform rational basis spline curves.

Braun and Borrmann (2019) proposed a method for automatically labelling construction images based on the combination of 4D Building Information Models and an inverse photogrammetry approach. They proved the feasibility of the developed methods by labelling procedure; it was applied to several real-world construction sites, providing over 30,000 automatically labelled elements. On the other hand, Sun et al. (2017b) priced a method for room views based on BIM and oblique photogrammetry. However, none of the aforementioned authors analyzed the feasibility of applying BIM together with photogrammetry techniques to small projects.

BIM use with photogrammetry support in small construction projects was not found in earlier literature, gap which is now covered in this work. The reconstruction projects face the high level uncertainty during implementation mostly due inappropriate information management, insufficient quality control and low competence of participants (Migilinskas et al., 2017).

The present work is aimed at assessing the profitability of BIM supported by photogrammetry in small projects through the analysis of a set of commercial franchises, for which implementation costs, execution periods and quality of outcomes have been accounted for. Moreover, a general approach for the identification of process patterns in BIM construction protocols using graph-based methodology is also presented. This way, project designers will be provided with a tool which might enhance outcomes' quality and work efficiency. 


\section{Methodology}

Figure 1 shows a schematic diagram of the methodology used in this study in order to compare BIM protocol with support of photogrammetric techniques with projects presented under CAD protocols.

Figure 2 shows an example of graphic results for the projects under study according to CAD and BIM protocols.

The following information was collected during the data acquisition process:

- Size and measurement data for the sample set of 121 projects involving constructed area of the sales area $\left(\mathrm{m}^{2}\right)$, constructed area of the remaining spaces in the shop $\left(\mathrm{m}^{2}\right)$, length of exterior façade $(\mathrm{m})$, surface for sign board, vinyls, window display, door and glass windows $\left(\mathrm{m}^{2}\right)$, length of main shelves and cosmetic furniture $(\mathrm{m})$.

- Times for data collection and times for CAD vs BIM3D data processing.

- Times for decision making since date of project delivery.

- Times for project execution and opening since the beginning of working activities.
BIM modelling was carried out with the legal corporate image of the franchise, involving furniture and signs.

Software packages Autodesk ${ }^{\otimes}$ 123D Catch were used to model small objects and products of the franchise, to place them in the furniture, and make the implantation real. Agisoft Photoscan ${ }^{\circ}$ were used to design 3D models for the selected element, which were photographed in controlled and uniform luminosity conditions, in absence of shadows and from different angles (Huang \& You, 2012). Such technique was applied to small objects and is similar to that of 3D modelling by traditional stereoscopic pairs (Morency et al., 2002). As an example, Figure 3 depicts a couple of 3D elements modelled with 123D Catch ${ }^{\circledR}$ and with Agisoft Photoscan ${ }^{\oplus}$, which, after the treatment, gives the 3D modelling of each object (as shown in the middle of the figure), and gives noise and those parts to be discarded (external part of the figure).

Once the 3D design was finished, it was added to the BIM family in REVIT ${ }^{\bullet}$ and/or SketchUp ${ }^{\circ}$, after exporting it with extensions like OBJ or DAE. SketchUp's Photomatch module provides a perspective adjustment method from a given $2 \mathrm{D}$ photogram, which allows the definition of three different axes by vanishing point calculation as

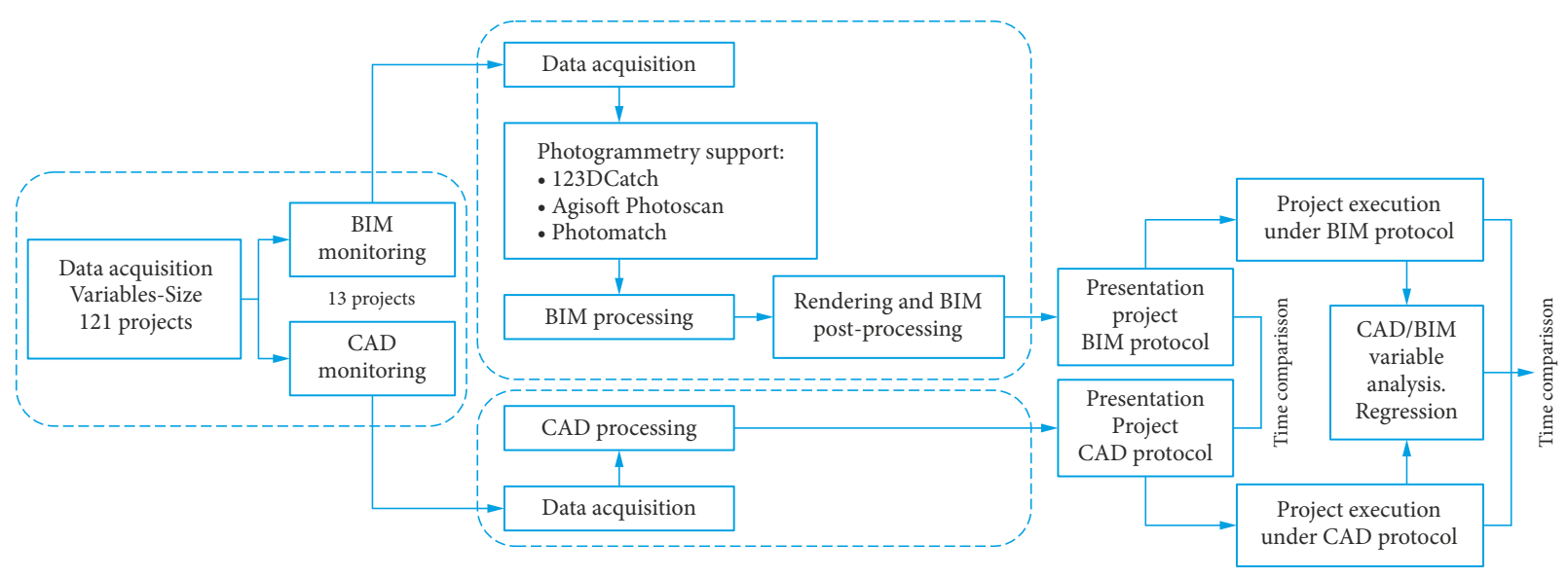

Figure 1. Schematic diagram of the methodology for comparison BIM vs CAD


Figure 2. Graphic outcomes corresponding to traditional CAD (left) and BIM (right) techniques (LBP file) 
well as the selection of horizontal and vertical sections in identifiable elements of the picture. This way, once the system had been defined, it could be transferred to the 3D model and hence provide a preliminary assembly prior to the project itself under the initial support of such photograph. Figures 4(a) and 4(b) illustrate how the axes were edited in photographic perspective and how the area to be inserted in the photograph was modelled independently.

The 3D model was then implanted in the selected space and directly inserted into the coordinate system, with the same perspective as that of the photograph. Photogrammetry techniques were used at object level in order to determine distances, based on perspective and vanishing points, amending the translation, rotation and scaling models, and integrating elements of the photogram directly related to the $3 \mathrm{D}$ model.

Provided the standard distances were known, the virtual model was inserted in the photogram using the same scale by selecting common points which were easily identifiable both in both images (like for instance corners). The final stage of the integration of the $3 \mathrm{D}$ model into the photogram in the same perspective system, as well as the export of the outcome as a preview image, are shown in Figures 5(a) and 5(b).

a)

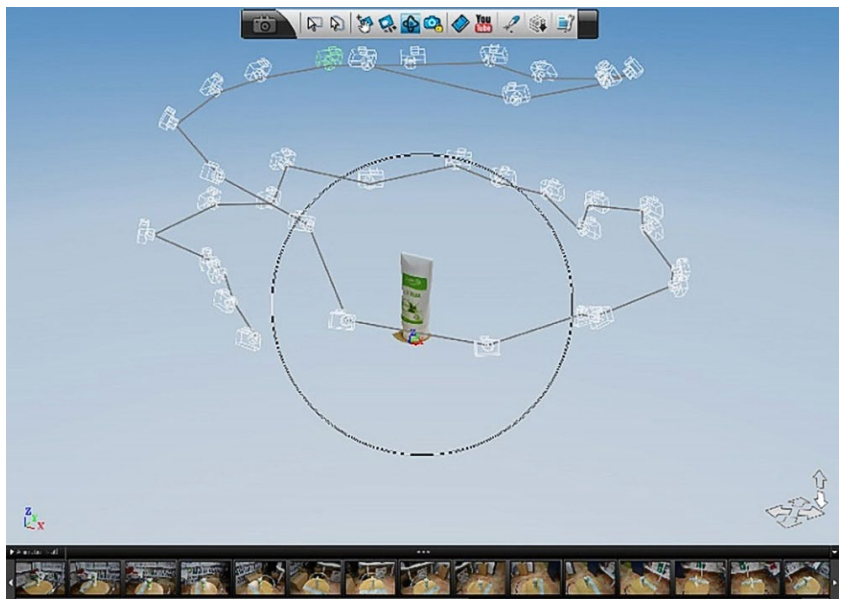

The more precision in the axes fitting and in the measurement of identifiable checkpoints in the photogram, the greater the accuracy in measurements in photographic elements (Arévalo Vera et al., 2015; Santa Cruz, 2003). The data acquisition process with the abovementioned system does not require the measurement of distances for all the relevant elements, but only for those regarded as checkpoints and indicators of the goodness of measurements. As a result, the sketching process is significantly simplified.

According to specific commercial offers, initial costs for the implementation of CAD and BIM processes were quantified as 7,412 $€$ and $24,117.93 €$, respectively.

Costs derived from the use of BIM, as compared to ordinary costs, were assessed by means of the calculation of the return of investment (ROI) (Autodesk, 2018).

$$
\mathrm{ROI}=\frac{\left(B-\left(\frac{B}{1+E}\right)\right) \times(12-C)}{A+(B \times C \times D)},
$$

where $A, B, C, D$ and $E$ represent the following: hardware and software costs including BIM and photogrammetry $(€)$, labour monthly costs $(€)$, estimated time for training

b)

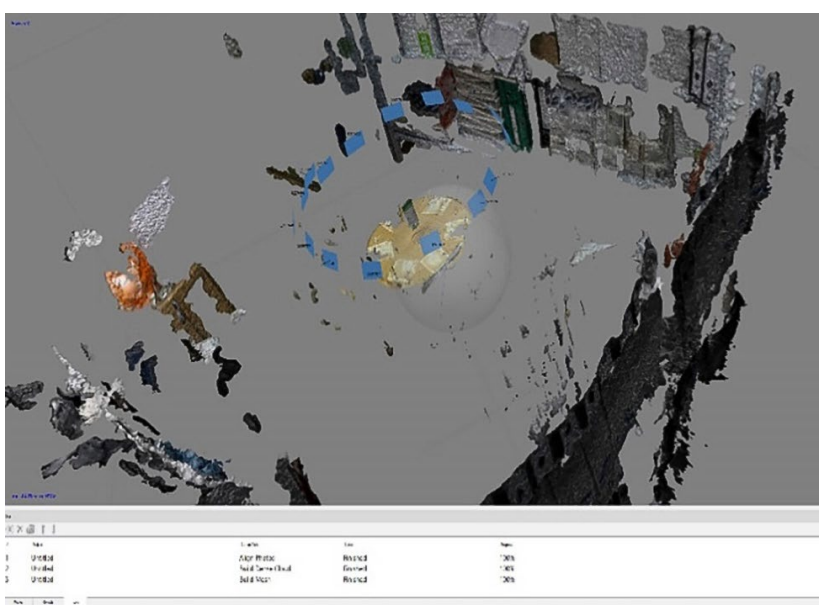

Figure 3. 3D element with 123D Catch ${ }^{\oplus}$ (a) and with Agisoft Photoscan ${ }^{\circledR}$ (b)

a)

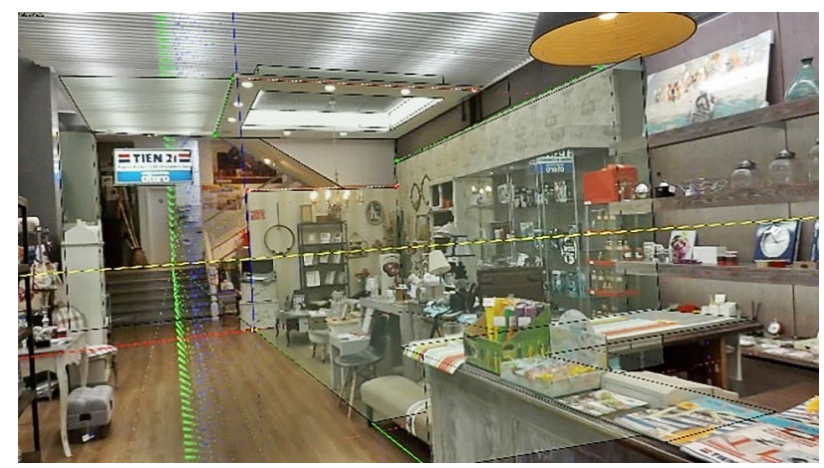

b)

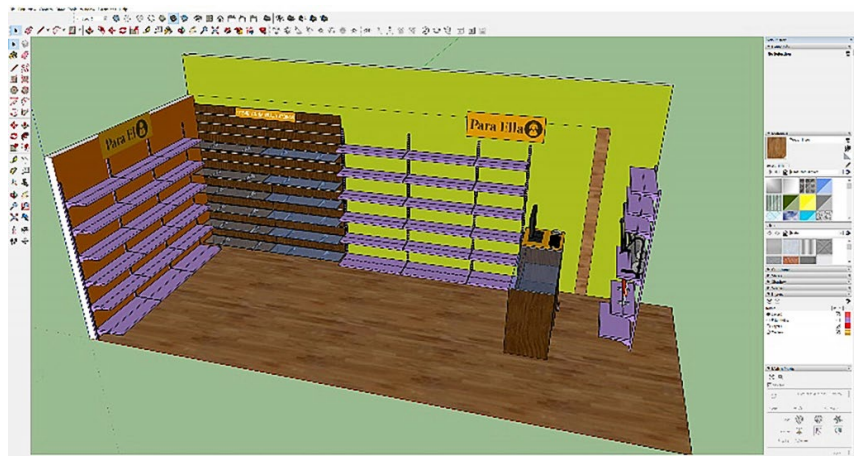

Figure 4. (a) and (b): Photomatch. Edition of axes and BIM modelling of the zone to be inserted in the photograph 
a)

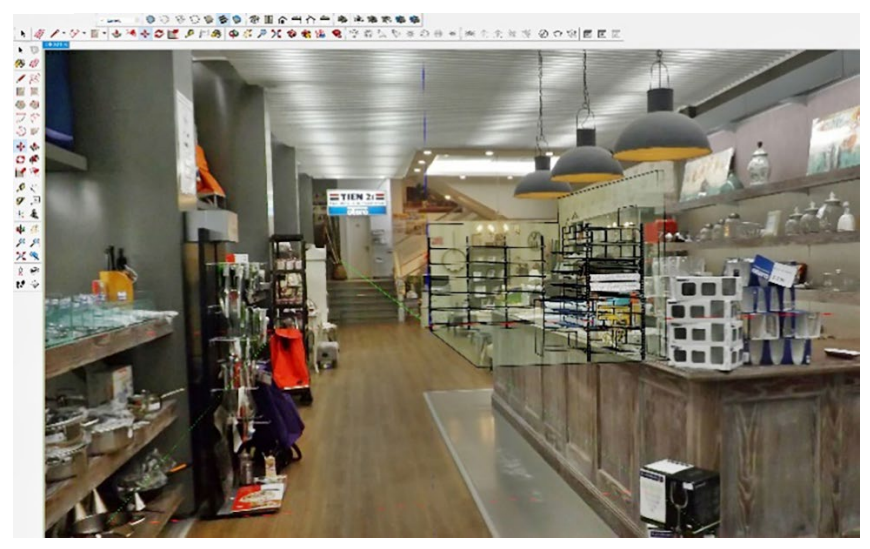

b)

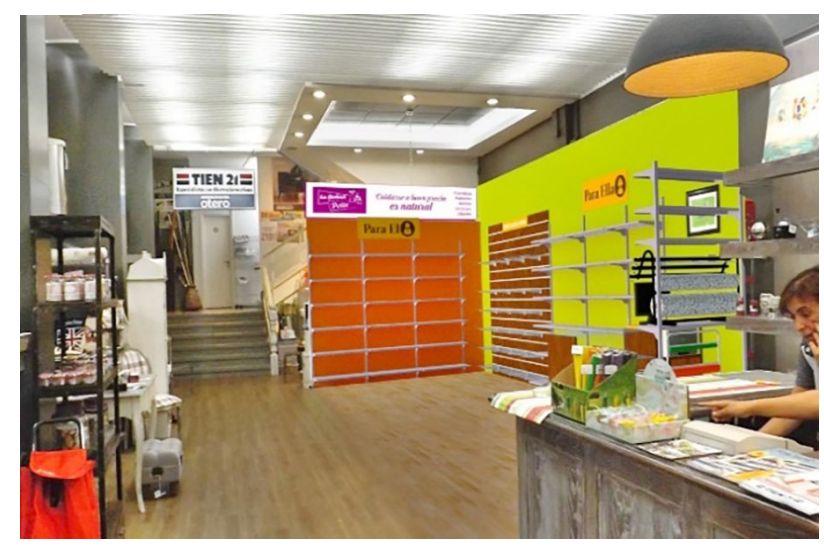

Figure 5. (a) and b): Integration of the 3D model and the photogram, and export of outcome image

for the use of BIM software and processing and photogrammetric capture processes (months), loss of productivity during training (\%), increase of productivity after training (\%), respectively.

On another note, a multiple regression analysis was carried out. For such purpose a specific independent variable referred to as "BIM / NoBIM" was defined, so that it was set as " 1 " for projects which underwent BIM-3D protocol, and " 0 " for those which did not.

The rest of the involved variables were the following: constructed area of the sales area $\left(\mathrm{m}^{2}\right)$, constructed area of rest of remaining rooms in the shop $\left(\mathrm{m}^{2}\right)$, length of exterior façade $(\mathrm{m})$, surface for sign board, vinyls, window display, door and glass windows $\left(\mathrm{m}^{2}\right)$, length of main shelves and cosmetic furniture $(\mathrm{m})$.

Two particular aspects were accounted for: the size of the sample and the number of variables. Also, the coefficient of determination $R^{2}$ was used to quantify the goodness of the fit of a given model to a particular variable. This coefficient increases as does the number of variables (Martínez Rodriguez, 2005). The number of degrees of freedom of the model, defined as the difference between the number of data and the number of coefficients of the equation, should therefore be analysed. A modified coefficient of determination was set for the "artificial" increment of $R^{2}$, defined so that it remained neutral against the introduction of additional variables (Ferraro et al., 2011).

The net present value (NPV) defined in Eqn (2) was used to assess the investment profitability (Phillips et al., 2011). The average value of the operations granted by Line ICO Business and Entrepreneurs, plus a $4 \%$ margin to prevent potential rises of Euribor, was used as the update rate:

$$
\mathrm{NPV}=\sum_{t=1}^{n} \frac{V_{t}}{(1+0.04)^{t}}-I_{0}
$$

$I_{0}$ being the cost of investment expressed in $€$, which accounts for the costs of investment in software and hardware (including 1,000 $€$ additional maintenance and technical support for computer equipment), and $V_{t}$ being the difference of annual incomes and expenses yielded by the investment.
As a complementary measure the internal rate of return (IRR, which represents the geometric mean of the expected future returns of an investment) was also accounted for. This way, the assessment of the investment for BIM implementation was accomplished by means of the calculation of the profitability of the updated collections and payments generated by the investment (Furlong et al., 2017), so that the investment would be regarded as feasible and profitable whenever the IRR exceeds the discount rate.

\section{Case study}

The study herein reported focused on 121 projects of commercial franchises in the ambit of perfume and cosmetic industries, which were financed by franchisees before their own shops were opened. Such projects were developed between 2011 and 2016 and were based in both BIM and CAD methodologies (only CAD for the first years and both CAD and BIM from 2015 on). Data collection sheets were used for the monitoring of time demand for each activity, from which the staff of the department of expansion and the technicians working on the projects obtained the net periods devoted to each of the individual activities involving CAD and BIM processes. Moreover, surveys to each franchise holder were also conducted in order to assess the perception on the outcomes of BIM protocols in terms of improvement of image and quality of the franchise.

The reliability of the data used in this study was guaranteed due to the fact that part of the research team participated directly in the development of the project with the company. All working times used were monitored and processed in databases.

As a first step after the analysis of the sampling set of 121 franchise projects, the potential correlations among the variables related to the size of the shop were identified. The relation between the constructed area of the sales zone and the length of shelves and showcases is depicted in Figure 6 for each of the projects under study. 
The sales zone was observed to have an average constructed area of $35.37 \mathrm{~m}^{2}$ (standard deviation $12.02 \mathrm{~m}^{2}$ ), and the average length of shelves and cosmetic showcases was computed as $13.18 \mathrm{~m}(2.31 \mathrm{~m})$, which yields $2.68 \mathrm{~m}$ shelves and showcases per $\mathrm{m}^{2}$ constructed area of the sales zone.

Figure 7 represents the time devoted to data acquisition and processing for each of the projects developed by means of CAD or BIM protocols. It was observed that the support photogrammetry and standardization of BIM processes improve traditional processing times.

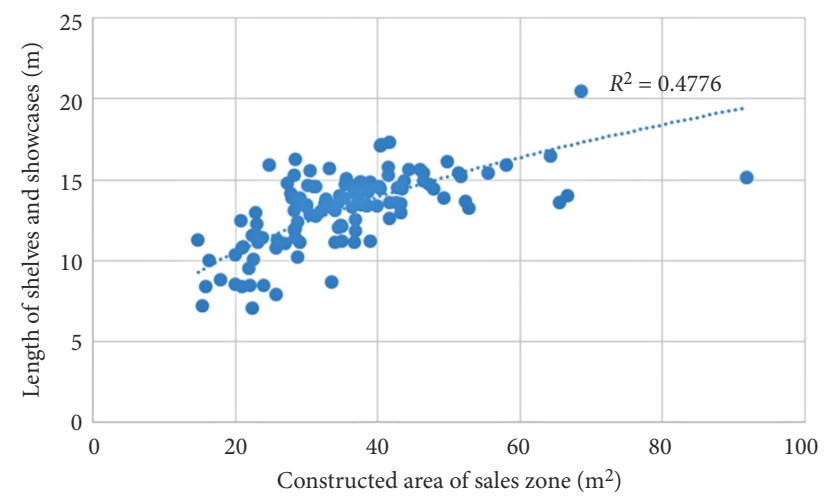

Figure 6. Relation between the constructed area of the sales zone and the length of shelves and showcases for each of the 121 projects under study
Figure 8 shows the mean execution time per unit useful area of the sales zone for the projects developed by CAD modelling, as well as the associated histogram. As can be observed, the time devoted to refurbishing/opening showed no dependence on the constructed area. In particular, the mean value was computed as 57.56 days (standard deviation 20.38 days).

The analogous Figure 9 for BIM-developed projects is depicted, with mean time 58.80 days, standard deviation 32.92 days and standard distribution 5.59.

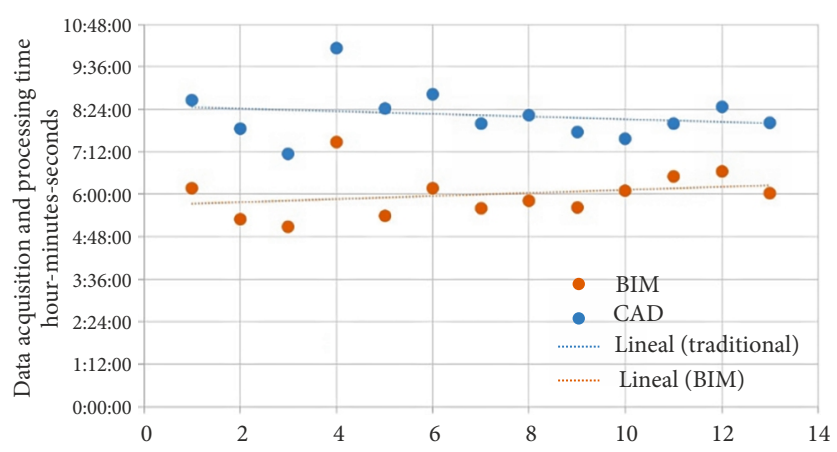

Figure 7. Time devoted to data acquisition and processing CAD / BIM
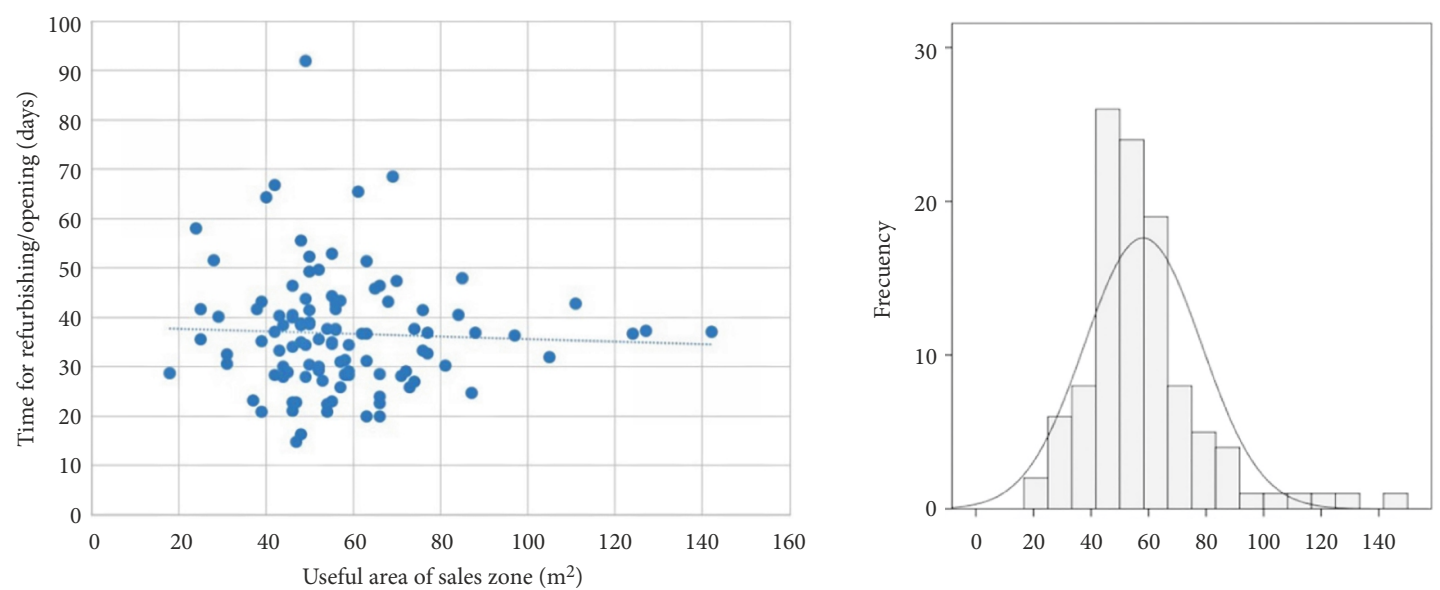

Figure 8. Time for refurbishing / opening as a function of useful area of the sales zone for CAD projects
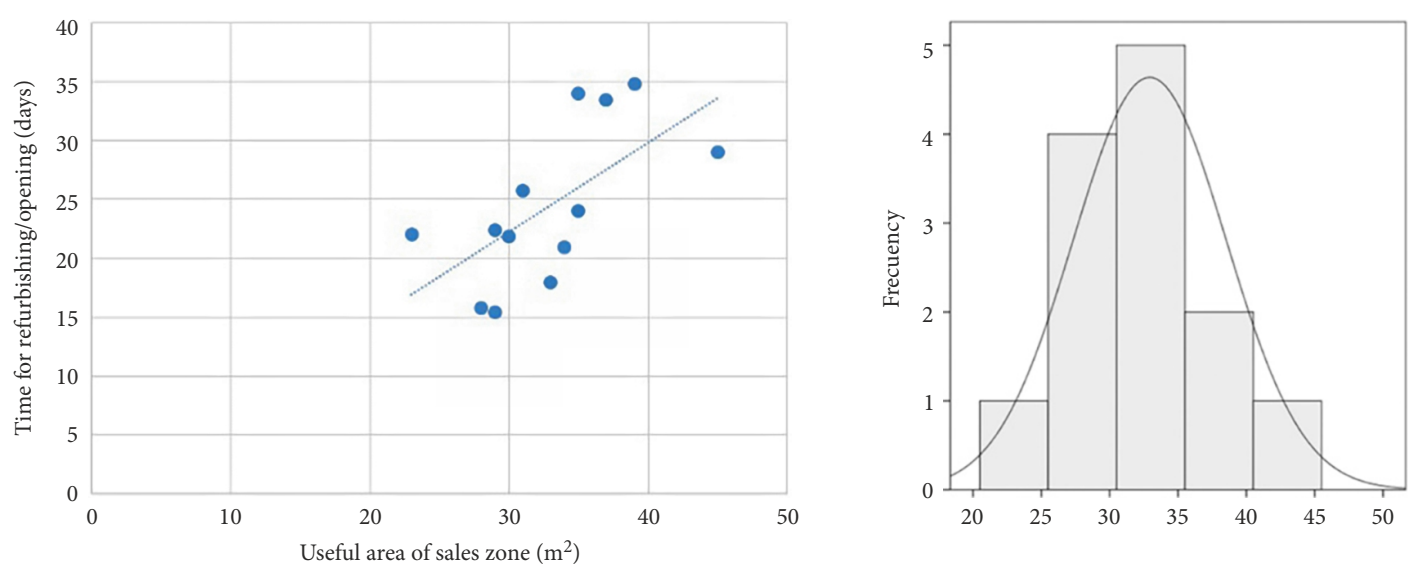

Figure 9. Time for refurbishing / opening as a function of useful area of the sales zone for BIM projects 
Table 1. Mean values for data involved in the sample set of projects under study

\begin{tabular}{|l|c|}
\hline Sales zone $\left(\mathrm{m}^{2}\right)$ & 35.37 \\
\hline Rest rooms $\left(\mathrm{m}^{2}\right)$ & 12.07 \\
\hline Exterior façade $(\mathrm{m})$ & 6.12 \\
\hline Door, windows, vinyls and window display $\left(\mathrm{m}^{2}\right)$ & 10.55 \\
\hline Shelves and cosmetic showcases $(\mathrm{m})$ & 13.18 \\
\hline
\end{tabular}

On another note, the study of the return of investment involved the separated analysis of processing costs for CAD- and BIM-developed projects, considering the costs in Spain and the average costs between 2015 and 2018, as a reference. Table 1 lists the mean values obtained for the variables related to the size of the project.

Time distributions for data processing after data acquisition are shown in the two following Figure 10. BIM protocol with photogrammetry support includes several unique processes, non-existing in $\mathrm{CAD}$, including point cloud cleaning process, 3D model design and virtual tour.

The main difference between the two methodologies lies in the fact that CAD processing requires the repetition of implantation of elements in different views (plant, elevation, profile, sections, etc.), while such process is automatically carried out in BIM. Furthermore, technical specifications of BIM elements are associated to metadata, which definitively speeds up their handling and post processing.

An improvement in decision time for BIM-developed projects was observed as compared to those corresponding to CAD methodology. Both methodologies were also compared as referred to the period between the date the project was delivered to the client and the date the client made the investment decision. Such period was observed as 5.85 days and 11.83 days for BIM- and CAD-delivered projects, respectively. In other words, BIM methodology was proved to shorten the period by 5.98 days in average.

A regression analysis for 3 and 6 independent variables was carried out accounting for the execution time differences for CAD vs BIM-3D methodologies. If BIM-3D protocol was applied, the refurbishing/opening period was observed to be shortened by 5.62 days according to the 6-variable regression model (4.41 days for the 3 -variable model). The values for the corrected coefficients of determination $R^{2}$ were computed as 0.8685 and 0.8676 for the 6and 3-variable regressions, respectively, which means that the variability for the dependent variable yielded by the two regression models were accordingly $86.85 \%$ and $86.76 \%$.

Although there are different available techniques to detect collinearity (Morrissey \& Ruxton, 2018), the analysis of coefficients allows to evaluate whether the model shows instability when a new variable is accounted for. For the particular case herein reported, the model did not undergo instability. However, no significant improvement in variability was achieved and therefore only the outcomes obtained by means of the 3 -variable model were used. Some anomalous values were assessed as referred to the refurbishing period (accounting for both anticipations and delays). Moreover, the sufficiency of BIM protocols was assessed to check if the outcomes were reliable enough in terms of the corrected $R^{2}$ coefficient, for which a value of 0.8911 was achieved. Also, the corresponding normal distribution plot was found to be quite close to the diagonal as depicted in Figure 11.

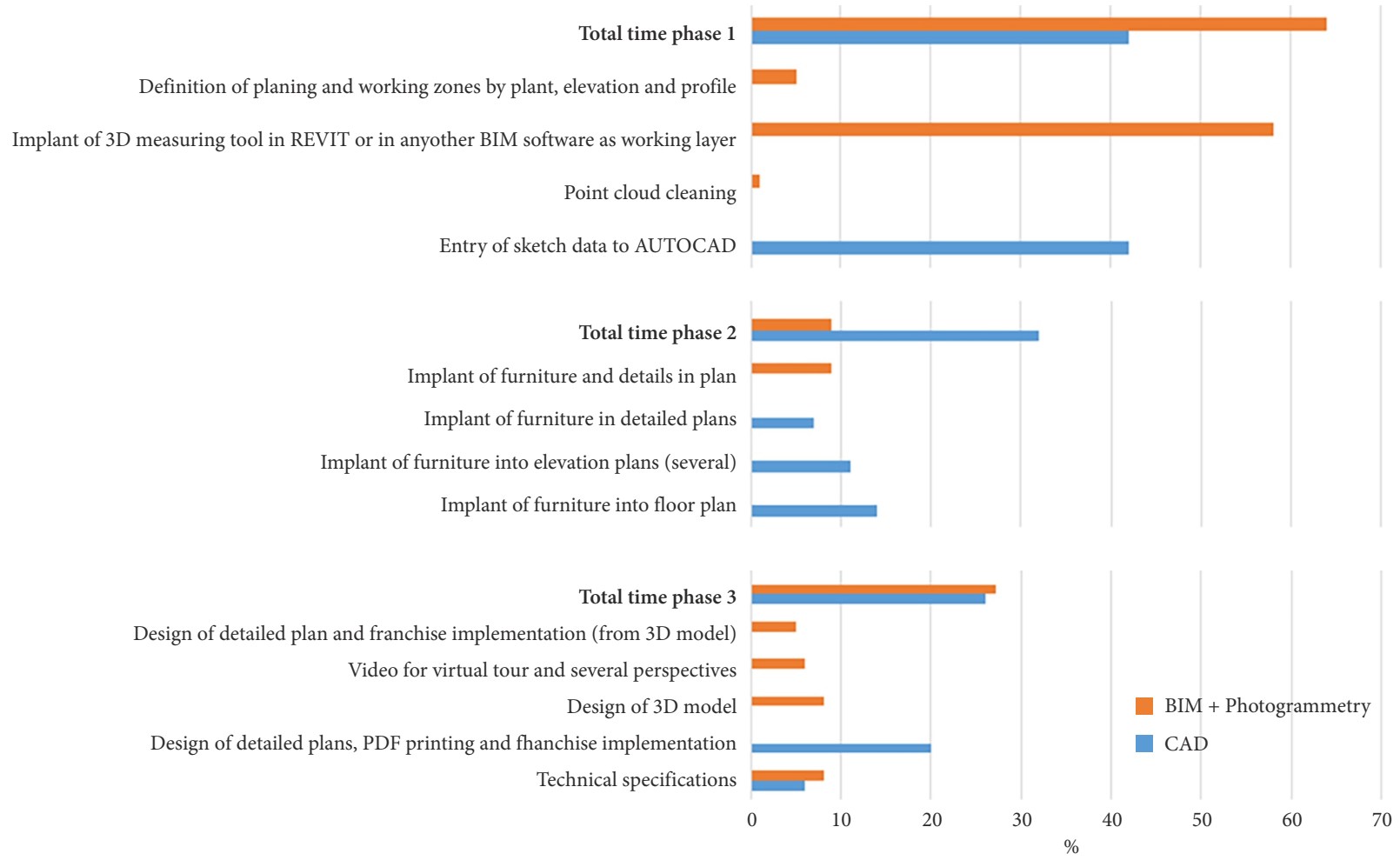

Figure 10. Time distribution for CAD and BIM processing after data acquisition 


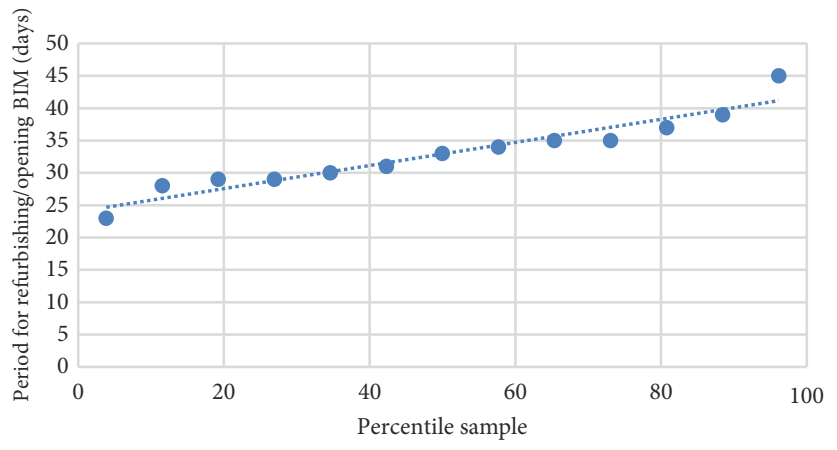

Figure 11. Plot for normal probability

As a result, the normality hypothesis was confirmed and data were therefore statistically validated, provided the graph represented both the theoretical and the empirical distribution functions of the standardized residuals (Tsokos \& Wooten, 2016). Therefore, provided the models and the variables under study had been accordingly validated, the anticipation in the franchise opening was assessed. For such purpose, a simulation accounting for the mean daily invoicing of the franchisee was carried out (set as $100 €$ intervals up to an average value of $600 €$, with several intervals for the gross estimated profit of the franchisor's sales ranging between 35\% and 45\%.

Labour costs were taken from Spain's National Statistics Institute (2016). The gained productivity was computed as $27.2 \%$, and the ROI corresponding to the first year was found to be $41.88 \%$. Table 2 lists the simulated values for the net present value (NPV) and for the IRR as referred to an intermediate step of $400 €$ daily billing with operating margin in the range $35 \%$ to $45 \%$.

Table 2. NPV and IRR simulation corresponding to an intermediate stage of the simulation

\begin{tabular}{|c|c|c|c|c|c|}
\hline \multicolumn{3}{|c|}{ NPV } & \multicolumn{3}{c|}{ IRR } \\
\hline $35 \%$ & $40 \%$ & $45 \%$ & $35 \%$ & $40 \%$ & $45 \%$ \\
\hline 1773.35 & 3771.42 & 5769.55 & $18.70 \%$ & $35.20 \%$ & $51.70 \%$ \\
\hline
\end{tabular}

\section{Discussion}

The achieved outcomes might be regarded as a contribution to sustainable construction, provided that three of its essential spheres (economic, social and environmental) were improved by the implementation of BIM and photogrammetry as compared to standard protocols, as shown in Figure 12. Moreover, with regard to the economic aspect, such implementation was not only sustainable, but yielded a favourable ROI with affordable costs that definitely improve the standard CAD processes.

The reduction of execution errors shows a direct impact on lower needs of materials as well as on optimization of use of raw materials (Reizgevičius et al., 2018). The application of the methodology herein reported to the project execution showed a clear advantage in terms of saving of consumables regarding paper, printing, etc.,

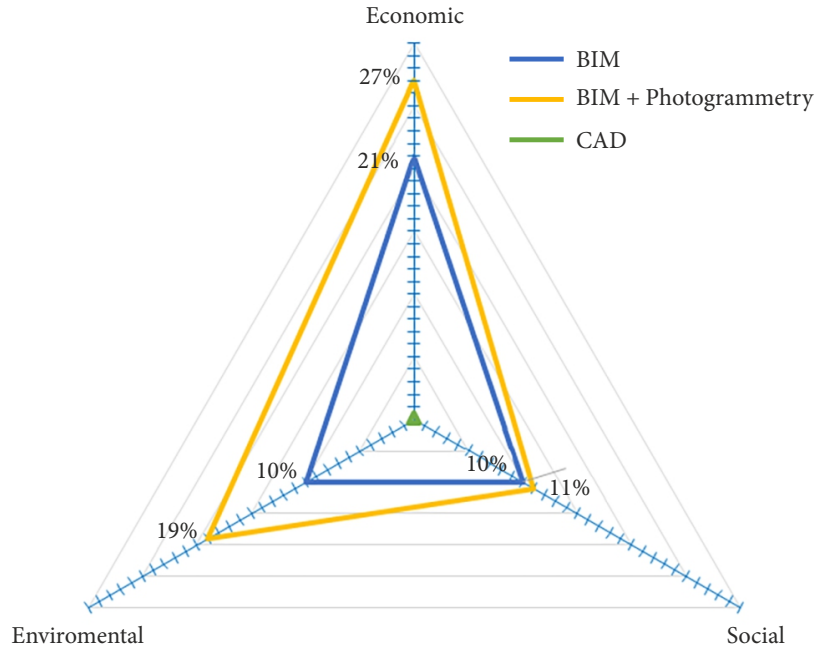

Figure 12. Improvements relating to the application of BIM and photogrammetry as compared to standard protocols

given that the associated costs were significantly reduced by means of digital support (shareable, duplicable and with no additional costs). In particular, data collection was drastically simplified by the use of digital photographic techniques (Laing et al., 2014).

Data collection and processing times were seen not to be relevant in order to compute the ROI; therefore the larger the project size, the more interesting the outcomes yielded by the implementation of the proposed techniques (Carretero-Ayuso et al., 2018). Many interface events and problems occur during the construction phase of construction projects, such that tracking and controlling these are essential to construction management (Lin, 2015).

The economic savings due to the implementation of BIM protocols were estimated as $54.76 €$ per project as referred to former technical operations, which indeed does not represent a relevant amount. A potential explanation might rely on the mean size of the projects, given that shops are small sales points $35.37 \mathrm{~m}^{2}$ in average located in commercial areas, for which BIM protocols do not allow significant differences as compare to CAD in terms of previous data collection and processing stages (Ustinovichius et al., 2018). However, the implementation of BIM for small projects is highly advisable, provided that productivity and execution time are strongly enhanced. As a result, pre-opening periods are reduced and both profitability and the ROI will subsequently be optimized (Furlong et al., 2017).

Implementation of BIM models in the construction phase, which typically involves participants from different fields, often has numerous BIM-related interfaces and problems (Lin et al., 2016). Processes might be further improved by optimization of earlier stages, data collection techniques and the preliminary sketch, with the support of photogrammetry for a more dynamic integration of BIM protocols. In fact, new computer packages devoted to the integration of data collection and automatic delineation on photo-frames are currently emerging to the market, 
which would presumably improve automatic data-dump processes as well as direct work on BIM implementation in 3D-models (Juan \& Hsing, 2017).

BIM techniques might definitely help improve the standard construction practices even for the case of minor refurbishing tasks, thus promoting sustainable construction as well as enhancing long-term quality and efficiency (Liu et al., 2017; Zamora-Polo et al., 2019).

As a further line of research, the reported methodology will be implemented to wider projects, like for instance those involving shopping centres or healthcare buildings.

\section{Conclusions}

Time savings in data collection as well as in BIM with photogrammetry processing were observed to yield an improvement in productivity exceeding $27 \%$ as compared to that of the standard CAD methodology. As a result, a positive economic impact on franchisors and franchisees was achieved due to a shorter period until shop opening and also to shorter project execution times. In addition, the number of the construction company's enquiries on project misinterpretations was reduced by $25 \%$.

Refurbishing time prior to opening was shown to be improved by BIM with photogrammetry support as compared to that of the standard CAD methodology. According to the considered regression model, such period was reduced by 4.11 days. Moreover, enhanced outcomes were achieved for the ROI associated to the implementation of BIM protocols (41.88\%) as compared to those corresponding to CAD methodology.

The computer simulation performed for the various options for BIM versus CAD implementation costs served as a clear justification for the investment on BIM protocols. Even if more resources and higher investment on hardware and software were accounted for - with almost double forecasted investment on resources, the use of BIM methodology was proved to be highly recommended $(\mathrm{ROI}=16.70 \%)$.

This research allows to improve and standardize the data collection processes as well as integrate photogrammetry in an automated way. The research can be directed to the automation of different proposals for implementation and optimization of furniture and elements in the available space, following the patterns that each franchise has established as image criteria.

The results of this study have been validated through their application to refurbishment and/or small construction works, which include furniture and posters related to the image of the company. Therefore, the validity of the results is limited to the scope of small works in commercial premises.

\section{Acknowledgements}

The authors wish to acknowledge the European Social Fund and University of Extremadura for the support for this research work. Also, the authors wish to acknowledge La Botica de los Perfumes for helpful and supportive collaboration.

\section{Funding}

This work was supported by research project GR-18029 linked to the VI Regional Plan of Research and Investigation from the General Government of Extremadura 2017-2020 financed by the European Regional Development Fund (FEDER).

\section{Author contributions}

Conceptualization, J.G.S.C.; methodology, J.G.S.C.; formal analysis, A.J.L.C.; investigation, A.J.L.C. and J.G.S.C.; resources, A.M.R.R.; writing - original draft preparation A.J.L.C.; writing - review and editing, J.G.S.C.; visualization, A.J.L.C..; supervision, J.G.S.C.; funding acquisition, J.G.S.C. and A.M.R.R.

\section{Disclosure statement}

Authors declare that they have not any competing financial, professional, or personal interests from other parties.

\section{References}

Arévalo Vera, B., Bayona Ibáñez, E., \& Rincón Parada, I. K. (2015). Methodology for 3D documentation using digital photogrammetry. Tecnura, 19, 113-120.

https://doi.org/10.14483/udistrital.jour.tecnu-ra.2015.SE1.a09

Autodesk. (2018). REVIT Building information modeling. BIM's return on investment. http://static.ziftsolutions.com/files/8a7c 9fef2693aale0126d282571c02c7

Barazzetti, L., Banfi, F., Brumana, R., \& Previtali, M. (2015). Creation of parametric BIM objects from point clouds using NURBS. The Photogrammetric Record, 30, 339-362. https://doi.org/10.1111/phor.12122

Barlish, K., \& Sullivan, K. (2012). How to measure the benefits of BIM - A case study approach. Automation in Construction, 24, 149-159. https://doi.org/10.1016/j.autcon.2012.02.008

Braun, A., Tuttas, S., \& Stilla, U. (2015). A concept for automated construction progress monitoring using BIM-based geometric constraints and photogrammetric point clouds. ITcon, 20(8), 68-79.

Braun, A., \& Borrmann, A. (2019). Combining inverse photogrammetry and BIM for automated labeling of construction site images for machine learning. Automation in Construction, 106, 102879. https://doi.org/10.1016/j.autcon.2019.102879

Candelario-Garrido, A., García-Sanz-Calcedo, J., \& Reyes Rodríguez, A. M. (2017). A quantitative analysis on the feasibility of $4 \mathrm{D}$ planning graphic systems versus conventional systems in building projects. Sustainable Cities and Society, 35, 378384. https://doi.org/10.1016/j.scs.2017.08.024

Carretero-Ayuso, M. J., Garcia-Sanz-Calcedo, J., \& RodríguezJiménez, C. E. (2018). Characterisation and appraisal of the technical specifications in the project of brick facades in Spain. Journal of Performance of Constructed Facilities, 32(3), 04018012.

https://doi.org/10.1061/(ASCE)CF.1943-5509.0001149

Dainty, A., Leiringer, R., Fernie, S., \& Harty, C. (2017). BIM and the small construction firm: a critical perspective. Building Research \& Information, 45(6), 696-709.

https://doi.org/10.1080/09613218.2017.1293940 
Doumbouya, L., Gao, G., \& Guan, C. (2016). Adoption of the Building Information Modeling (BIM) for construction project effectiveness: The review of BIM benefits. American Journal of Civil Engineering and Architecture, 4(3), 74-79.

Ferraro, M. B., Colubi, A., González-Rodríguez, G., \& Coppi, R. (2011). A determination coefficient for a linear regression model with imprecise response. Environmetrics, 22(4), 516-529. https://doi.org/10.1002/env.1056

Furlong, C., De Silva, S., Gan, K., Guthrie, L., \& Considine, R. (2017). Risk management, financial evaluation and funding for wastewater and stormwater reuse projects. Journal of Environmental Management, 191, 83-95.

https://doi.org/10.1016/j.jenvman.2017.01.007

Ghaffarianhoseini, A., Tookey, J., Ghaffarianhoseini, A., Naismith, N., Azhar, S., Efimova, O., \& Raahemifar, K. (2017). Building Information Modelling (BIM) uptake: Clear benefits, understanding its implementation, risks and challenges. Renewable and Sustainable Energy Reviews, 75, 1046-1053. https://doi.org/10.1016/j.rser.2016.11.083

Giel, B. K., \& Issa, R. A. A. (2013). Return on investment analysis of using Building Information Modeling in construction. Journal of Computing in Civil Engineering, 27(5), 511-521. https://doi.org/10.1061/(ASCE)CP.1943-5487.0000164

Huang, J., \& You, S. (2012). Point cloud matching based on 3D self-similarity. In 2012 IEEE Computer Society Conference on Computer Vision and Pattern Recognition Workshops. Providence, RI, USA.

https://doi.org/10.1109/CVPRW.2012.6238913

Jernigan, F. (2008). Big BIM little BIM: the practical approach to Building Information Modeling integrated practice done the right way! (2nd ed.). Salisbury.

Juan, Y.-K., \& Hsing, N.-P. (2017). BIM-based approach to simulate building adaptive performance and life cycle costs for an open building design. Applied Science, 7(8), 837.

https://doi.org/10.3390/app7080837

Khaja, M., Seo, J. D., \& McArthur, J. J. (2016). Optimizing BIM metadata manipulation using parametric tools. Procedia Engineering, 145, 259-266.

https://doi.org/10.1016/j.proeng.2016.04.072

Koranda, C., Chong, W. K., Kim, C., Chou, J. S., \& Kimet, C. (2012). An investigation of the applicability of sustainability and lean concepts to small construction projects. KSCE Journal of Civil Engineering, 16(5), 699-707.

https://doi.org/10.1007/s12205-012-1460-5

Laing, R., Leon, M., Mahdjoubi, L., \& Scott, J. (2014). Integrating rapid $3 \mathrm{D}$ data collection techniques to support BIM design decision making. Procedia Environmental Sciences, 22, 120-130. https://doi.org/10.1016/j.proenv.2014.11.012

Lévy, F. (2011). BIM in small-scale sustainable design. John Wiley \& Sons. https://doi.org/10.1002/9781119572619

Li, J. (2014). From CAD to the rapid development of BIM. Applied Mechanics and Materials, 580-583, 3175-3178.

https://doi.org/10.4028/www.scientific.net/AMM.580-583.3175

Lin, Y. C. (2015). Use of BIM approach to enhance construction interface management: a case study. Journal of Civil Engineering and Management, 21(2), 201-217.

https://doi.org/10.3846/13923730.2013.802730

Lin, Y. C., Lee H. Y., \& Yang, T. (2016). Developing as-built BIM model process management system for general contractors: A case study. Journal of Civil Engineering and Management, 22(5), 608-621. https://doi.org/10.3846/13923730.2014.914081

Liu, Y., Van Nederveen, S., \& Hertogh, M. (2017). Understanding effects of BIM on collaborative design and construction:
An empirical study in China. International Journal of Project Management, 35(4), 686-698.

https://doi.org/10.1016/j.ijproman.2016.06.007

Martínez Rodriguez, E. (2005). Errores frecuentes en la interpretación del coeficiente de determinación lineal. Anuario Jurídico y Económico Escurialense, 38, 315-332.

Migilinskas, D., Pavlovskis, M., Urba, I., \& Zigmund, V. (2017). Analysis of problems, consequences and solutions for BIM application in reconstruction projects. Journal of Civil Engineering and Management, 23(8), 1082-1090.

https://doi.org/10.3846/13923730.2017.1374304

Mill, T., Alt, A., \& Liias, R. (2014). Combined 3D building surveying techniques - terrestrial laser scanning (TLS) and total station surveying for BIM data management purposes. Journal of Civil Engineering and Management, 19(Supplement 1), S23-S32. https://doi.org/10.3846/13923730.2013.795187

Moayeri, V., Moselhi, O., \& Zhu, Z. (2017). BIM-based model for quantifying the design change time ripple effect. Canadian Journal of Civil Engineering, 44(8), 626-642.

https://doi.org/10.1139/cjce-2016-0413

Morency, L.-P., Rahimi, A., \& Darrell, T. (2002). Fast 3D model acquisition from stereo images. In Proceedings of the First International Symposium on 3D Data Processing Visualization and Transmission. Padova, Italy.

https://doi.org/10.1109/TDPVT.2002.1024057

Morrissey, M. B., \& Ruxton, G. D. (2018). Multiple regression is not multiple regressions: the meaning of multiple regression and the non-problem of collinearity. Philosophy, Theory, and Practice in Biology, 10(3).

http://dx.doi.org/10.3998/ptpbio.16039257.0010.003

Omar, T., \& Nehdi, M. L. (2016). Data acquisition technologies for construction progress tracking. Automation in Construction, 70, 143-155.

https://doi.org/10.1016/j.autcon.2016.06.016

Phillips, J. J., Brantley, W., \& Phillips, P. P. (2011). Project management ROI: A step-by-step guide for measuring the impact and ROI for projects. Wiley.

https://doi.org/10.1002/9781118122587

Reizgevičius, M., Ustinovičius, J., Cibulskiene, D., Kutut, V., \& Nazarko, L. (2018). Promoting sustainability through investment in Building Information Modeling (BIM) technologies: A design company perspective. Sustainability, 10(3), 600. https://doi.org/10.3390/su10030600

Santa Cruz, A. J. (2003). La fotogrametría digital en el levantamiento de planos de edificios. Informes de la Construcción, 55, 31-40. https://doi.org/10.3989/ic.2003.v55.i488.539

Sanhudo, L., Ramos, N. M. M., Poças Martins, J., Almeida, R. M. S. F., \& Cardoso,V. (2020). A framework for insitu geometric data acquisition using laser scanning for BIM modelling. Journal of Building Engineering, 28, 101073.

https://doi.org/10.1016/j.jobe.2019.101073

Santos, R., Aguiar-Costa, A., Silvestre, J. D., \& Pyl, L. (2019). Informetric analysis and review of literature on the role of BIM in sustainable construction. Automation in Construction, 103, 221-234. https://doi.org/10.1016/j.autcon.2019.02.022

Sigalov, K., \& König, M. (2017). Recognition of process patterns for BIM-based construction schedules. Advanced Engineering Informatics, 33, 456-472.

https://doi.org/10.1016/j.aei.2016.12.003

Solís-Rodríguez, V., \& González-Díaz, M. (2017). Differences in contract design between successful and less successful franchises. European Journal of Law and Economics, 44(3), 483-502. https://doi.org/10.1007/s10657-015-9497-9 
Spain's National Statistics Institute. (2016). Labor cost components (Quarter 4/2015).

http://www.ine.es/dyngs/INEbase/es/operacion.htm

Sun, C., Jiang, S., Skibniewski, M. J., Man, Q., \& Shen, L. (2017a). A literature review of the factors limiting the application of BIM in the construction industry. Technological and Economic Development of Economy, 23(5), 764-779. https://doi.org/10.3846/20294913.2015.1087071

Sun, T., Xu, Z., Yuan, J., Liu, C., \& Ren, A. (2017b). Virtual experiencing and pricing of room views based on BIM and oblique photogrammetry. Procedia Engineering, 196, 11221129. https://doi.org/10.1016/j.proeng.2017.08.071

Tsokos, C., \& Wooten, R. (2016). The joy of finite mathematics. Elsevier.

Tuttas, S., Braun, A., Borrmann, A., \& Stilla, U. (2015). Validation of BIM components by photogrammetric point clouds for construction site monitoring. ISPRS Annals of Photogrammetry, Remote Sensing \& Spatial Information Sciences, 2, 231237. https://doi.org/10.5194/isprsannals-II-3-W4-231-2015

Ustinovichius, L., Popov, V., Cepurnaite, J., Vilutienè, T., \& Miedziałowski, C. (2018). BIM-based process management model for building design and refurbishment. Archives of Civil and Mechanical Engineering, 18(4), 1136-1149. https://doi.org/10.1016/j.acme.2018.02.004

Wang, H., Shen, S., \& Lu, X. (2012). Comparison of the camera calibration between photogrammetry and computer vision. In Proceedings of 2012 International Conference on System Science and Engineering (ICSSE) (pp. 358-362). Dalian, Liaoning, China. https://doi.org/10.1109/ICSSE.2012.6257207

Won, J., \& Lee, G. (2016). How to tell if a BIM project is successful: A goal-driven approach. Automation in Construction, 69, 34-43. https://doi.org/10.1016/j.autcon.2016.05.022

Zamora-Polo, F., Sánchez-Cortés, M. M., Reyes-Rodríguez, A. M., \& Sanz-Calcedo, J. G. (2019). Developing project manager's competences using Building Information Modeling. Applied Sciences, 9(19), 4006. https://doi.org/10.3390/app9194006

Zhang, M., Pan, Z., Huang, X., Xiang, N., Wang, S., \& Zhu, P. (2014). EasyHome: An online virtual home decoration system. Journal of Visualization and Computer Animation, 25(2), 101-113. https://doi.org/10.1002/cav.1549

Zou, Y., Kiviniemi, A., \& Jones, S. W. (2017). A review of risk management through BIM and BIM-related technologies. Safety Science, 97, 88-98.

https://doi.org/10.1016/j.ssci.2015.12.027 